\title{
Impact of unauthorized celebrity endorsements on cardiovascular healthcare
}

\author{
Farouk Mookadam*,1, Mehmet Oz², Tariq Jamal Siddiqi ${ }^{3}$, Diana Almader-Douglas ${ }^{4}$, \\ Michael Crupain ${ }^{5}$ \& Muhammad Shahzeb Khan ${ }^{6}$ \\ ${ }^{1}$ Department of Cardiovascular Medicine, Mayo Clinic, Phoenix, AZ 55902, USA \\ ${ }^{2}$ Department of Surgery, Columbia/New York Presbyterian Medical Center, New York, NY 10032, USA \\ ${ }^{3}$ Department of Internal Medicine, Dow University of Health Sciences, Karachi, 74200, Pakistan \\ ${ }^{4}$ Department of Education, Mayo Clinic, Phoenix, AZ 55902, USA \\ ${ }^{5}$ Department of Environmental Health \& Engineering, Johns Hopkins Bloomberg School of Public Health, Baltimore, MD 21205, \\ USA \\ ${ }^{6}$ Department of Internal Medicine, John H Stroger Jr. Hospital of Cook County, Chicago, IL 60612, USA \\ *Author for correspondence: Tel.: +1 480301 6801; Fax: +1 480301 8018; mookadam.farouk@mayo.edu
}

\section{"Unauthorized endorsements usually contain deceptive labels and products, and more importantly may adversely impact the health of consumers."}

First draft submitted: 11 April 2019; Accepted for publication: 23 August 2019; Published online: 10 October 2019

Keywords: cardiovascular disease $\bullet$ celebrity influence $\bullet$ consumer behavior $\bullet$ deceptive promotions $\bullet$ fake celebrity endorsement $\bullet$ false health advertisements • health care $\bullet$ health-related products and procedures • legitimate health products

Celebrities possess immense influence on the beliefs, interests and behavior of their audience [1,2]. The introduction of direct-to-consumers advertising has extended the use of this 'influence' for the sale of health-related products and procedures [3]. With such high exposure and the internet's ability to globalize a celebrity, the audiences can increase rapidly. These endorsements have the ability to influence dramatic changes in consumer behavior.

\section{Examples of celebrity endorsements}

As an example, in 2015 Kim Kardashian posted information about the morning sickness drug 'Diclegis' on her Instagram account. The post was 'liked' $>450,000$ times and shared among her 42.4 million followers [4]. As the Washington Post reports, the drug received 'pop-culture cred' [5]. After a prominent American television host underwent a live colonoscopy, a sustained 9-month increase in the number of colonoscopies was observed by a panel of 400 specialists [6]. In another instance in 2000, a survey conducted by the American Heart Association (AHA) found only $34 \%$ of women in the USA were aware that cardiovascular disease is the leading cause of death in women greater than age of 25 years [7]. In recognition of this problem many celebrities - such as Star Jones collaborated with the AHA to raise awareness among women about their risk; this led to increased understanding of cardiovascular disease among women [8].

\section{Purpose of this editorial}

Celebrity medical advice is being adopted by the public with increasing frequency. The motivation behind celebrity endorsement may be personal, emotional, altruistic or to enhance public knowledge of a disease or condition. Nonetheless, the publicity generated is immense. The mechanisms behind the influence of celebrity status are ensconced within multidisciplinary sciences that span the domains of economics, marketing, psychology and sociology [9].

Some corporations and advertisers may falsely leverage the fame of celebrities to help promote products and services [10-12]. Unauthorized endorsements usually contain deceptive labels and products, and more importantly may adversely impact the health of consumers. The results of a comprehensive systematic review, conducted using the protocol established by Hoffman et al., demonstrated a lack of primary research and data regarding the use of fake celebrity advertisements and its effects [13]. These findings are surprising, given that this type of fraud 
is rampant in today's marketplace, not only in the USA, but also in burgeoning economies such as India and China [14]. In light of current data, we will discuss effects of such endorsements and measures that can be taken to identify unauthorized celebrity endorsements and mitigate any negative impact that they may have on the societal health.

\section{Impact on consumer}

Perhaps the greatest threat these deceptive promotions pose is to the consumers' health and property. A celebrity's success is commonly generalized to all their traits, biasing the public opinion to view them as reliable medical advisers [15]. Hence, people may consume falsely endorsed healthcare products and procedures with the same intentions. Nevertheless, these items will likely be of no benefit or even cause harm. For example, thousands of women around the world who are trying to lose weight are claimed to have been misled by an internet celebrity diet scam, which used fake endorsements from famous names such as Victoria Beckham and Adele to promote their 'Raspberry Ketone Diet' [16. However, there is currently no evidence that raspberry ketone supplements can cause weight loss in humans [17]. Perhaps one of the biggest problems in today's marketplace is the false endorsements and promotion of dietary supplements for cardiovascular protection. It is estimated that around $\$ 31$ billion per year is earned in revenue from supplements sales and by 2025, the dietary supplement market is expected to be worth around $\$ 200$ billion [18]. However, studies have shown that almost all mineral, vitamin and other forms of nutritional supplements are not linked with cardiovascular protection [19]. In fact, some studies have suggested that combined vitamin $\mathrm{D}$ and calcium supplements are associated with increased risk for stroke.

\section{Impact on celebrities}

Alongside consumers, celebrities are also victims of this fraud. Celebrities signify important cultural and social meanings for many individuals [20]. Promotion of dubious items under their name may threaten their reputation and compromise the celebrity's efforts in publicizing and encouraging health behaviors of proven benefit. This would be a great loss, as active efforts by celebrities in raising health awareness are extremely important. For example, politician Bob Dole collaborated with Pfizer to raise awareness about erectile dysfunction and actor Sally Fields starred in advertisements for Boniva, an osteoporosis medication for postmenopausal women. Perhaps the most notable example is large-scale community-based public communication intervention in collaboration with celebrities, aimed at preventing cardiovascular disease. These programs have yielded improvements in risk-reducing behaviors, such as increase in physical activity and changes to diet [21].

\section{Impact on economy}

The US Government Accountability Office has found that in the USA counterfeiting has resulted in decreased innovation, loss of trade revenues, higher rates of unemployment and overall slower economic growth. Globally, it is estimated that counterfeiting has resulted in the loss of 2.5 million jobs and more than $\$ 70$ billion in tax revenue losses among the G20 economies [22]. Since healthcare is roughly $18 \%$ of the economy, we estimate the loss in tax revenues alone from the sector is over $\$ 12$ billion.

The settlements are limited since the legal system cannot keep up with rapidly evolving digital marketing practices. For example, after years of abuse, in 2013 the Federal trade commission (FTC) shut down numerous fake websites aiming to market 'acai berry supplements' and other weight loss products. But the pace and magnitude of settlements increased in 2017 when the FTC reached a $\$ 179$ million settlement with Tarr, Inc, the amount that the FTC alleges consumers nationwide paid the defendants over a period of $>5$ years [23]. This is just one of many internet marketing companies making unsubstantiated health claims. However, the most important obstacle may be the major internet technology companies, which inadvertently provide a marketplace for these fake products and false advertisements.

\section{Identifying fake endorsements}

Years of litigation and enforcement will be required to reduce fake advertising. In the meantime, consumers must protect themselves using tips that can help them identify fake celebrity endorsements. We have outlined a few important points below: 
- Products that use the terms 'as seen on' should be dealt with suspicion and avoided. Some companies will cover their tracks by using a very large gray area and using words along the line 'as aired during keeping up with the Kardashians' or 'as seen on The Dr Oz Show';

- The quality of product packaging should also be carefully assessed. Honest companies will not only spend millions of dollars on celebrity endorsements, but also on high production value. Whereas illegitimate companies will often release a product hastily with misspelled words and poorly edited work;

- News and media outlets usually do not promote products on their sites. The consumer should double check the web address/URL/social media account/email, and make sure it is authentic. For instance, the site for Forbes should be 'forbes.com' not 'phorbes.com';

- Legitimate health products are less likely to offer you 'free trials' and make 'limited time offers'.

\section{Conclusion}

In the future, it is crucial that the cardiologists and other healthcare professionals work with celebrities in order to counter the negative influences of fake celebrity healthcare endorsements. First, cardiologists should speak to their patients about the legitimacy of celebrity advice and the source of the health information. Comments by patients of recent celebrity endorsements should not be received with annoyance, but rather as a crucial opportunity to start educational conversations about cardiovascular health. Second, a certification/registration process or database by the FTC or equivalent regulatory body, should be formed to double-check whether a celebrity actually allowed a company or advertiser to use his or her persona, body or reputation to endorse a product or service related to cardiovascular health. Ultimately, there is an urgent need for large-scale studies to help researchers better understand where people receive false advertisements and what compels them to act on this false information.

\section{Financial \& competing interests disclosure}

The authors have no relevant affiliations or financial involvement with any organization or entity with a financial interest in or financial conflict with the subject matter or materials discussed in the manuscript. This includes employment, consultancies, honoraria, stock ownership or options, expert testimony, grants or patents received or pending, or royalties.

No writing assistance was utilized in the production of this manuscript.

\section{References}

1. Viale PH. Celebrities and medicine: a potent combination. J. Adv. Pract. Oncol. 5(2), 82-84 (2014).

2. Tanne JH. Celebrity illnesses raise awareness but can give wrong message. BMJ 321(7269), 1099 (2000).

3. Ransohoff DF, Ransohoff RM. Sensationalism in the media: when scientists and journalists may be complicit collaborators. Eff. Clin. Pract. ECP 4(4), 185-188 (2001).

4. Landa J. How celebrity drug endorsements can harm public health. Fox News (2015). www.foxnews.com/health/2015/08/31/how-celebrity-drug-endorsements-can-harm-public-health.html

5. Cha AE. Study raises questions about efficacy of morning sickness pill endorsed by Kim Kardashian. The Washington Post (2017). www.washingtonpost.com/news/to-your-health/wp/2017/01/04/study-raises-questions-about-efficacy-of-morning-sickn ess-pill-endorsed-by-kim-kardashian/?noredirect=on\&utm_term=.84246c92e9bd.

6. Cram P, Fendrick AM, Inadomi J, Cowen ME, Carpenter D, Vijan S. The impact of celebrity promotional campaign on the use of colon cancer screening: the Katie Couric effect. Arch. Intern. Med. 163(13), 1601-1605 (2003).

7. Long T, Taubenheim A, Wayman J, Temple S, Ruoff B. 'The heart truth': using the power of branding and social marketing to increase awareness of heart disease in women. Soc. Mar. Q. 14(3), 3-29 (2008).

8. Olya G. Celebrities who have opened up about heart health (2017). https://people.com/health/celebrities-heart-health/

9. Hoffman SJ, Tan C. Following celebrities' medical advice: meta-narrative analysis. BMJ 347, f7151 (2013).

10. Mady MS. Celebrity drug endorsements: are consumers protected? Am. J. Law Med. 43(1), 139-160 (2017).

11. Jaslow R. Paula Deen \& company: 10 celebs who help sell drugs. $C B C$ News (2012). www.cbsnews.com/media/paula-deen-company-10-celebs-who-help-sell-drugs/3/

12. Lee BY. Spotting fake celebrity endorsements of diet and health remedies. Forbes (2016). www.forbes.com/sites/brucelee/2016/10/03/s potting-fake-celebrity-endorsements-of-diet-and-health-remedies/\#493ae34ffdb2

13. Hoffman SJ, Mansoor Y, Natt N et al. Celebrities' impact on health-related knowledge, attitudes, behaviors, and status outcomes: protocol for a systematic review, meta-analysis, and meta-regression analysis. Syst. Rev. 6(1), 13 (2017).

14. Highya Research Team. Fake celebrity endorsements - what they are and how you can avoid them (2014). www.highya.com/articles-guides/fake-celebrity-endorsements-what-they-are-how-you-can-avoid-them 
15. Leuthesser L, Kohli CS, Harich KR. Brand equity: the halo effect measure. Eur. J. Mark. 29(4), 57-66 (1995).

16. Poulter S. Diet scam advert that faked claims from Adele and Victoria Beckham is banned (2013). www.dailymail.co.uk/news/article-2348589/Diet-scam-advert-faked-claims-Adele-Victoria-Beckham-banned.html

17. Gunnars K. Do raspberry ketones really work? a detailed review. Healthline (2018). www.healthline.com/nutrition/do-raspberry-ketones-work\#section4

18. Grand View Research. Dietary supplements market worth $\$ 194.63$ billion by 2025 CAGR $7.8 \%$ (2019). www.grandviewresearch.com/press-release/global-dietary-supplements-market

19. Khan SU, Khan MU, Riaz $\mathrm{H}$ et al. Effects of nutritional supplements and dietary interventions on cardiovascular outcomes: an umbrella review and evidence map. Ann. Intern. Med. 171(3), 190-198 (2019).

20. Choi SM, Rifon NJ. Who is the celebrity in advertising? Understanding dimensions of celebrity images. J. Pop Cult. 40(1), 304-324 (2007).

21. Shea S, Basch CE. A review of five major community-based cardiovascular disease prevention programs. Part II: intervention strategies, evaluation methods, and results. Am. J. Health Promot. 4(4), 279-287 (1990).

22. Global Innovation Policy Center. Measuring the magnitude of global counterfeiting: creation of a contemporary global measure of physical counterfeiting (2016). www.theglobalipcenter.com/measuring-the-magnitude/

23. Federal Trade Commission. Internet marketers of dietary supplement and skincare products banned from deceptive advertising and billing

practices (2017). www.ftc.gov/news-events/press-releases/2017/11/internet-marketers-dietary-supplement-skincare-products-banned 